\title{
SUPERAÇÃO DA DORMÊNCIA E AVALIAÇÃO DA QUALIDADE FISIOLÓGICA DE SEMENTES DE Sesbania virgata
}

\author{
Dormancy break and evaluation of physiological quality of Sesbania virgata seeds
}

\author{
Valquíria Nogueira Camargos ${ }^{1}$, Maria Laene Moreira de Carvalho², \\ Dejânia Vieira de Araújo ${ }^{3}$, Flávio Henrique Linhares Magalhães ${ }^{4}$
}

\begin{abstract}
RESUMO
A avaliação da qualidade fisiológica de lotes de sementes de Sesbania virgata é dificultada pela dormência inerente à espécie, bem como pela inadequação metodológica de testes disponíveis. Para desenvolver procedimentos adequados à avaliação da qualidade das sementes de $S$. virgata, foram avaliados métodos tanto para quebra de dormência como para realização do teste de tetrazólio. Em uma primeira fase, as sementes de cinco lotes foram submetidas a tratamentos para quebra de dormência: lixa, ácido e corte do tegumento, previamente ao teste de germinação. Para caracterização dos lotes e adequação da metodologia do teste de tetrazólio, na segunda fase, as sementes foram lixadas na região oposta ao eixo embrionário, e submetidas aos seguintes testes: tetrazólio, germinação, velocidade de emergência, peso de matéria fresca e de matéria seca de plântulas. Foram utilizados dois métodos de pré-condicionamento: embebição em papel por $18 \mathrm{~h}$ a $30^{\circ} \mathrm{C}$ e imersão em água por $12 \mathrm{~h}$ a $30^{\circ} \mathrm{C}$ e três períodos (uma, duas e três horas) de imersão em solução de tetrazólio $0,5 \%$. Na análise do perfil dos lotes de $S$. virgata foram detectadas variações na qualidade fisiológica pelos resultados dos testes de vigor e germinação. O método de escarificação com lixa possibilitou a quebra de dormência das sementes de $S$. virgata, e o pré-condicionamento das sementes em papel com embebição em solução de tetrazólio $0,5 \%$ por duas horas é um procedimento adequado para avaliação da viabilidade das sementes.
\end{abstract}

Termos para indexação: Viabilidade, tetrazólio, vigor, Sesbania virgata.

\begin{abstract}
The evaluation of Sesbania virgata seed physiological quality is hampered by its intrinsic seed dormancy and inadequate methodologies among available tests. To develop an adequate procedure to evaluate $S$. virgata seed quality, methods for dormancy breaking and tetrazolium test accomplishment were evaluated. In a first stage, seeds from five lots were submitted to dormancy breaking methods: sandpaper, acid and tegument cuts, followed by germination tests. To characterize lots and adapt a tetrazoliumtest, in a second stage, seeds were sanded in the area opposite to the embryonic axis and submitted to the following tests: tetrazolium, germination, vigor index, fresh and dry weight. Two preconditioning conditions (soaked paper for $18 \mathrm{~h}$ at $30^{\circ} \mathrm{C}$ and immersion in water for $12 \mathrm{~h}$ at $30^{\circ} \mathrm{C}$ ) and three immersion timespan (one, two and three hours) in tetrazolium solution $0.5 \%$ were used. In the $S$. virgata lot profile analysis, variations were detected in its physiological quality according to vigor index and germination results. Scarification method with sandpaper better broke S. virgata seed dormancy, and preconditioning seeds in soaked paper followed by immersion in tetrazolium solution for two hours was the appropriate procedure to assess seed viability.
\end{abstract}

Index terms: Viability, tetrazolium, vigour index, Sesbania virgata.

(Recebido em 18 de maio de 2006 e aprovado em 2 de janeiro de 2007)

\section{INTRODUÇÃO}

Sesbania virgata é uma espécie do gênero Sesbania (Fabaceae), conhecida popularmente como saraizinho, feijãozinho e mãe-josé (POTT \& POTT, 1994). A planta é utilizada em paisagismo e na recuperação de matas ciliares (EVANS, 1990) e sua propagação por sementes é dificultada pela dormência, comum nessa espécie (VEASEY et al., 2000).
Apesar das espécies do gênero Sesbania apresentarem diferentes níveis de dormência, Veasey et al. (2000) afirmaram que a dormência de sementes está relacionada a impermeabilidade do tegumento, havendo necessidade de desenvolvimento de métodos adequados para escarificação das mesmas, para que o potencial real do lote seja manifestado tanto no campo como em testes para avaliação da qualidade fisiológica. Lotes com elevado grau de dormência podem permanecer no solo ou substrato

\footnotetext{
'Bióloga, Mestranda em Virologia - Departamento de Fitopatologia/DFP - Universidade Federal de Lavras/UFLA - Cx. P. 3037 - $37200-000$ - Lavras, MG - valquiriabio@yahoo.com.br

2Doutora em Fitotecnia-Sementes, Professora - Departamento de Agricultura/DAG - Universidade Federal de Lavras/UFLA - Cx. P. 3037 - $37200-000$ Lavras, MG - mlanemc@ufla.br

${ }^{3}$ Engenheira Agrônoma, Doutor em Patologia de Sementes - Departamento de Agronomia/DA - Universidade do Estado do Mato Grosso/UFMT Rodovia MT 358, Km 07 - Jardim Aeroporto - Cx. P. 287 - 78300-000 - Tangará da Serra, MT - dejania@terra.com.br

${ }^{4}$ Doutor em Patologia de Sementes - Rua Firmino Lopes Câmara, 1615 - Centro - 35510-000 - Carmo do Cajuru, MG - flaviohlm@yahoo.com.br
}

Ciênc. agrotec., Lavras, v. 32, n. 6, p. 1858-1865, nov./dez., 2008 
por vários meses, sem que ocorra germinação. Segundo Ferreira \& Borguetti (2004) são relativamente recentes os estudos sobre os mecanismos, as modalidades e os métodos de superação de dormência em espécies tropicais.

Tratamentos para quebra de dormência em sementes do gênero Sesbania como ácido sulfúrico durante 40 minutos para $S$. speciosa (WEERAKOON \& SENEVIRATNE, 1992); imersão em água fervente por 60 segundos para sementes da espécie $S$. sesban (JAMWAL \& DUTT, 1995), vêm sendo testados nos últimos 15 anos.

A dormência pode também acarretar problemas na avaliação da qualidade fisiológica, já que o teste de germinação é o principal método utilizado, tanto por apresentar procedimentos padrões como por informar o potencial de emergência em condições ideais (MARCOS FILHO, 2005). Este teste apresenta sérias limitações, principalmente para espécies nativas, cujas sementes geralmente exigem longos períodos para germinar (ZUCARELI et al., 2001).

A avaliação da qualidade fisiológica das sementes por meio de testes mais rápidos, que proporcionem resultados reproduzíveis, tem sido uma busca constante dos tecnologistas de sementes. Entre os testes considerados rápidos, o teste de tetrazólio vem se destacando em programas de controle de qualidade, pois além de avaliar a viabilidade e o vigor, permite a identificação de fatores que afetam o desempenho das sementes (KRZYZANOWSKI et al., 1991).

Devido à falta de informações na literatura a respeito de métodos de avaliação da qualidade, bem como sobre os procedimentos a serem adotados para realização do teste de tetrazólio em sementes de $S$. virgata, este trabalho foi planejado e executado, objetivando-se desenvolver metodologias para superação da dormência, bem como, de avaliar diferentes metodologias do teste de tetrazólio na avaliação de qualidade fisiológica de sementes de $S$. virgata.

\section{MATERIAL E MÉTODOS}

Os experimentos foram realizados no Laboratório de Análise de Sementes do Departamento de Agricultura da Universidade Federal de Lavras-UFLA, em Minas Gerais. Foram utilizadas sementes de $S$. virgata coletadas no Município de Lavras e armazenadas em câmara fria a $10^{\circ} \mathrm{C}$. Os cinco lotes de sementes utilizados foram designados conforme o seu percentual de germinação inicial $(60 \%)$ e a sua safra, sendo estes: lote 1 e 2 da safra 1993, lote 3 safra 1995, lote 4 safra 2001, e lote 5 safra 1997.

Foram realizados dois experimentos, sendo testados, no primeiro experimento, três métodos para quebra de dormência: 1 - Lixa: neste método as sementes foram escarificadas uma a uma com uma lixa $\mathrm{n}^{\circ} 120$, adaptada a um esmeril; 2 - Corte do tegumento: o corte foi realizado com o auxilio de um bisturi, na região oposta ao eixo embrionário; e 3 - Ácido sulfúrico: imersão das sementes durante 15 minutos em ácido sulfúrico PA, seguida por lavagem em água corrente e secagem sobre papel toalha. Foram utilizadas sementes sem escarificação como testemunha.

Na determinação da velocidade de embebição das sementes dos diferentes lotes, foram retiradas amostras de 25 sementes após serem submetidas a cada tratamento de quebra de dormência, foram colocadas sobre uma folha de papel germitest umedecida e acondicionada em BOD, à temperatura de $30^{\circ} \mathrm{C} \pm 2{ }^{\circ} \mathrm{C}$. A cada duas horas, as sementes foram pesadas com o intuito de determinar a quantidade de absorção de água pela semente, procedimento adotado até o inicio da protrusão radicular.

As sementes foram submetidas ao teste de germinação de acordo com as recomendações descritas para $S$. exaltata, nas Regras para Análise de Sementes (BRASIL, 1992). As avaliações foram realizadas aos cinco, sete e 14 dias após o início do teste. Este experimento foi realizado em delineamento inteiramente casualizado em esquema fatorial 5 x 3 (cinco lotes e três métodos de quebra de dormência). As análises dos dados foram realizadas no programa estatístico SISVAR (FERREIRA, 2000) e as médias comparadas pelo teste de Scott-Knott e regressão de acordo com a natureza dos dados.

Após a identificação do método mais adequado para a quebra de dormência, realizou-se o segundo experimento, no qual os lotes foram caracterizados fisiologicamente quanto à metodologia do teste de tetrazólio para a espécie $S$. virgata. Foram também efetuadas avaliações como: germinação, emergência de plântulas em campo e pesos da matéria verde e seca. O teste de emergência foi conduzido em canteiro, tendo como substrato terra e areia na proporção de $2: 1$ com quatro repetições de 50 sementes/lote. Determinou-se o estande inicial aos cinco dias e o estande final aos 21 dias após a semeadura. $\mathrm{O}$ índice de velocidade de emergência foi obtido por contagens diárias de plântulas emergidas e calculado utilizando-se os critérios indicados por Maguire (1962). $\mathrm{Na}$ determinação do peso da matéria verde, as plântulas de cada parcela do teste de emergência foram cortadas rente ao solo e pesadas em balança analítica com precisão de três casas decimais. Após a pesagem, as plântulas foram colocadas em sacos de papel e levadas para estufa onde permaneceram por 24 horas a $60{ }^{\circ} \mathrm{C}$, sendo novamente pesadas para a obtenção do peso da matéria seca.

A adequação da metodologia do teste de tetrazólio foi realizada avaliando-se o pré-condicionamento em papel 
umedecido e em gerbox contendo água. No précondicionamento em papel as sementes foram envolvidas por papel germitest umedecido com água destilada e armazenadas em caixas tipo gerbox, em seguida, levadas para BOD com $30{ }^{\circ} \mathrm{C} \pm 2{ }^{\circ} \mathrm{C}$ por 18 horas. No précondicionamento em água as sementes foram colocadas diretamente em água, em caixas gerbox e estas acondicionadas em BOD a $30{ }^{\circ} \mathrm{C} \pm 2{ }^{\circ} \mathrm{C}$ por 12 horas. Após o pré-condicionamento, as sementes foram cortadas na porção distal do eixo embrionário, tendo o tegumento e a membrana remanescente, retirados manualmente. Para coloração foi utilizada a concentração de $0,5 \%$ da solução de tetrazólio descrita por Zayat (1996) para S. virgata e testados três períodos de embebição (uma, duas e três horas). Posteriormente, as sementes foram mantidas em BOD, a $30^{\circ} \mathrm{C} \pm 2{ }^{\circ} \mathrm{C}$, no escuro. Utilizou-se delineamento inteiramente casualizado, em esquema fatorial 2 × 3 × 5 (duas metodologias de pré-condicionamento, três períodos de embebição e cinco lotes). A análise estatística foi realizada no programa SISVAR (FERREIRA, 2000), e as médias comparadas pelo teste de Tukey.

\section{RESULTADOS E DISCUSSÃO}

No primeiro experimento referente à quebra de dormência de sementes de $S$. virgata, houve variação na absorção de água pelas sementes submetidas aos três tratamentos: lixa, ácido e corte do tegumento (Figura 1). No tempo de 22 horas as sementes tratadas com ácido sulfúrico tinham absorvido maior volume de água que as sementes submetidas aos tratamentos com lixa e corte do tegumento. Resultados semelhantes foram obtidos por Smiderle \& Sousa (2003), ao estudar métodos para quebra de dormência em sementes de Paricarana da família Fabaceae-Papilionidae (Bowdichia virgilioides Kunth), observando que a escarificação com lixa por um minuto e o tratamento com ácido sulfúrico por cinco minutos possibilitaram maior absorção de água em relação aos demais tratamentos testados (imersão em ácido sulfúrico por 10 minutos, imersão em álcool etílico por cinco e 10 minutos).

Apesar da absorção inicial de água pelas sementes escarificadas com ácido ter sido maior nas primeiras horas de embebição, ao final do período de 22 horas o tratamento com lixa possibilitou o mesmo resultado enquanto o corte do tegumento proporcionou maior absorção (Figura 1).

Pelos resultados da análise estatística dos dados referentes à germinação dos lotes de $S$. virgata, não houve diferença significativa na germinação dos lotes submetidos à lixa, ao ácido ou corte do tegumento, entretanto foram detectadas diferenças na germinação das sementes dos lotes utilizados, independentemente do método de escarificação (Tabela 1).

Foram observados três níveis de qualidade fisiológica dos lotes, sendo o lote 1 superior e os lotes 4 e 5 , inferiores.

As sementes que não foram submetidas à quebra de dormência (testemunha) não embeberam ou iniciaram a germinação 21 dias após a semeadura, confirmando a necessidade de tratamentos para superação da dormência em sementes dessa espécie como já observado por Veasey et al. (2000).

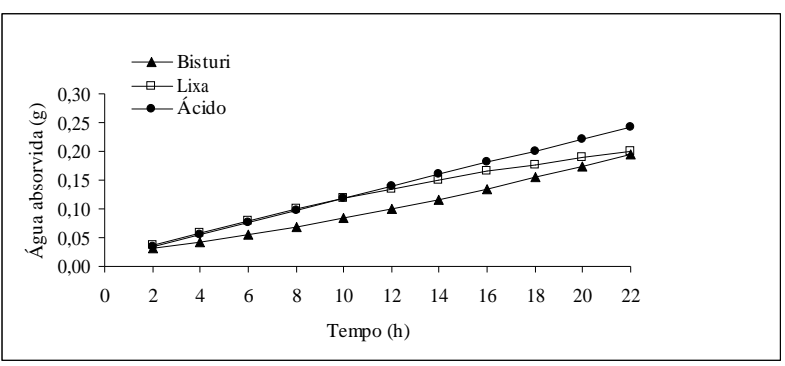

Figura 1 - Tempo de embebição dos lotes de sementes de Sesbania virgata, submetidos à escarificação com lixa, ácido e corte do tegumento (bisturi).

Tabela 1 - Percentagem da germinação dos lotes de sementes de Sesbania virgata, submetidos os tratamentos para superar a dormência.

\begin{tabular}{cccccc}
\hline \multicolumn{5}{c}{ Germinação $(\%) *$} \\
\hline Lotes & testemunha & Lixa & Ácido & Bisturi & Média \\
\hline 1 & 0,0 & 94 & 89 & 92 & $90 \mathrm{a}$ \\
2 & 0,0 & 84 & 87 & 85 & $85 \mathrm{~b}$ \\
3 & 0,0 & 85 & 84 & 86 & $83 \mathrm{~b}$ \\
4 & 0,0 & 75 & 78 & 78 & $78 \mathrm{c}$ \\
5 & 0,0 & 77 & 81 & 70 & $76 \mathrm{c}$ \\
\hline $\mathrm{CV}(\%)$ & & 8,59 & & \\
\hline
\end{tabular}

* Médias com a mesma letra maiúscula nas linhas não diferem pelo teste Scott-Knott $(\leq 0,05 \%)$. 
O tratamento com ácido sulfúrico proporcionou a rápida escarificação das sementes, no entanto, causou lesões no hipocótilo e nas raízes das plântulas. Em vários trabalhos, o tratamento com ácido sulfúrico foi empregado com sucesso para superar a dormência das sementes de Stylosanthes scabra (ARAÚJO et al., 2002), de Bixa orellana L. (AMARAL et al., 1995) e de Bauhinia monandra Britt, (ALVES et al., 2000). Apesar deste método ser amplamente utilizado, certos cuidados devem ser tomados, uma vez que longos períodos de exposição causam danos às sementes e redução da germinação (MARCOS FILHO, 1999).

Apesar do método do corte do tegumento com bisturi ter apresentado resultados satisfatórios em sementes de melancia (Citrullus lanatus Thunb) (OLIVEIRA, 2002), este não foi viável na escarificação de sementes da espécie em estudo em conseqüência da baixa aplicabilidade do método, pois $S$. virgata apresenta sementes muito pequenas e tegumento rígido. Além disso, a embebição das sementes foi irregular resultando em baixa germinação.

A escarificação pela lixa foi eficiente para superação da dormência de sementes de várias espécies com tegumento impermeável, dentre elas, Stylosanthes guianenses e Bauhinia racemosa (PRASAD \& NAUTIYAL, 1996); Bauhinia ungulata (ALVES et al., 2000). Para semente de $S$. virgata foi verificado maior número de plântulas normais com relação às sementes submetidas ao ácido e ao corte com bisturi. Com base nestas informações, o método de escarificação com a lixa foi utilizado para a quebra de dormência das sementes na segunda etapa do trabalho.

No segundo experimento foram detectadas variações na qualidade fisiológica dos diferentes lotes utilizados (Tabela 2). Em todas as avaliações, o lote 1 (safra 1993) apresentou melhor qualidade fisiológica quando comparado com os demais lotes, tanto com relação ao percentual de germinação quanto pelos testes de vigor, com exceção do estante inicial, onde não foi observada diferença entre os lotes. Pelas determinações de estante final e velocidade de emergência de plântulas, o lote 5 apresentou desempenho inferior quando comparado com os outros lotes testados (Tabela 2).

As épocas de colheita dos lotes não influenciaram no percentual de germinação, permanecendo viáveis, os lotes com maior tempo de armazenamento, de forma que o lote 1 apresentou maior porcentagem de germinação, (Tabela 2).

Resultados semelhantes foram contatados por Araújo et al. (2004) que, ao estudar o efeito da germinação em sementes de $S$. virgata sem tegumento, observou que o período de 21 dias foi suficiente para determinar o índice de velocidade de emergência com percentual médio de germinação do lote de $52 \%$ e por Teixeira (1979) que, a escarificação do tegumento com lixa apresentou percentual de germinação de $82 \%$ em lotes de sementes de Stylosanthes guianenses com o uso deste tratamento.

$\mathrm{Na}$ adequação do teste de tetrazólio em sementes de $S$. virgata, vale ressaltar que se fez necessária a retirada do tegumento e da membrana remanescente expondo o cotilédone e o embrião à solução de tetrazólio $0,5 \%$. Esta exposição da semente é um fator importante para varias espécies florestais e frutíferas por apresentarem cotilédones densos e impermeáveis dificultando a absorção desta solução (BHERING et al., 2005; ZUCARELLI et al., 2001).

Os métodos de pré-condicionamento tanto em papel por 18 horas quanto em água por 12 horas apresentaram-se eficientes para a absorção de água das sementes, possibilitando a retirada do tegumento e da membrana remanescente sem danificar o embrião em todos os lotes (Tabela 3). Segundo Copeland et al. (1959), o précondicionamento antes da coloração constitui uma das etapas críticas do teste. Este autor acrescentou que a absorção lenta de água em temperatura controlada é necessária para evitar fratura no embrião. Em estudos

Tabela 2 - Avaliação da qualidade fisiológica de sementes de diferentes lotes de Sesbania virgata.

\begin{tabular}{ccccccc}
\hline \multicolumn{7}{c}{ Testes $(\%)^{*}$} \\
\hline Lotes & Germinação & EI & EF & IVE & PV & PS \\
\hline 1 & $92 \mathrm{a}$ & 4,00 & $98 \mathrm{a}$ & $5,51 \mathrm{a}$ & $22,52 \mathrm{a}$ & $2,31 \mathrm{a}$ \\
2 & $85 \mathrm{ab}$ & 0,00 & $90 \mathrm{~b}$ & $4,75 \mathrm{bc}$ & $18,92 \mathrm{~b}$ & $1,91 \mathrm{~b}$ \\
3 & $82 \mathrm{~b}$ & 0,00 & $97 \mathrm{a}$ & $4,66 \mathrm{c}$ & $19,60 \mathrm{~b}$ & $1,99 \mathrm{~b}$ \\
4 & $73 \mathrm{c}$ & 3,50 & $93 \mathrm{ab}$ & $5,19 \mathrm{ab}$ & $19,32 \mathrm{~b}$ & $2,02 \mathrm{ab}$ \\
5 & $66 \mathrm{~d}$ & 7,00 & $80 \mathrm{c}$ & $4,65 \mathrm{c}$ & $17,85 \mathrm{~b}$ & $1,83 \mathrm{~b}$ \\
\hline $\mathrm{CV}(\%)$ & 10,64 & 4,36 & 5,81 & 11,77 & 8,32 & 3,56 \\
\hline
\end{tabular}

* Médias com mesma letra, nas colunas, não diferem entre si pelo teste de Tukey $(\mathrm{P} \leq 0,05)$.

$\mathrm{EI}$ = estande inicial; $\mathrm{EF}$ = estande final; IVE = índice de velocidade de emergência; $\mathrm{PV}$ = peso da matéria verde; $\mathrm{PS}$ = peso da matéria seca. 
realizados por Zucareli et al. (2001), com espécies de plantas que possuem sementes de testa dura, dentre os métodos de pré-condicionamento utilizados destacaram-se: a punção, o corte e a retirada do tegumento que permitiram a absorção do sal de tetrazólio pelas estruturas internas dessas sementes. Em sementes de $S$. virgata, estas fraturas não foram detectadas nos embriões em conseqüência da presença do tegumento e da membrana remanescente que recobriam toda a semente, inclusive o embrião.

$\mathrm{Na}$ análise do vigor das sementes de $S$. virgata dos cincos diferentes lotes observou-se que independentemente do tipo de pré-condicionamento, o lote 1 nos períodos de uma, duas e três horas de permanência na solução de tetrazólio $0,5 \%$ apresentou maior vigor, em comparação aos demais (Tabela 3).

Pelo método de pré-condicionamento das sementes em água por 12 horas observou-se que as sementes do lote 1 apresentaram maior vigor em todos os períodos estudados. Quanto ao tempo de absorção na solução de tetrazólio a $0,5 \%$ com as sementes pré-condicionadas em água não foram observadas diferenças significativas.

Ferreira et al. (2001), estudando teste para avaliação rápida do vigor em sementes de soja (Pterodon pubescens Benth - Fabaceae), observaram que o teste de tetrazólio mostrou-se satisfatório a uma concentração de $0,075 \%$ durante 4 horas a $30^{\circ} \mathrm{C}$, sendo recomendado para programa de controle de qualidade de sementes.

Outro fator que deve ser levado em consideração na avaliação do vigor e na viabilidade de sementes é o tempo de execução do teste. Neste sentido Costa et al. (1998), mencionaram a redução do período de embebição das sementes de soja de 16 horas a $25^{\circ} \mathrm{C}$ para 6 horas a $41{ }^{\circ} \mathrm{C}$.

Em sementes florestais o tempo de execução do teste de tetrazólio pode ser reduzido quando se utilizam métodos de pré-condicionamento e escarificação
(BITTENCOURT \& VIEIRA, 1997). De acordo com Ferreira et al. (2001), os resultados referentes ao teste de tetrazólio devem ser relacionados com a temperatura, tempo de condicionamento e concentração de solução em cada espécie estudada, além da utilização do précondicionamento adequado.

Na Figura 2, as sementes de S. virgata, após serem submetidas ao teste de tetrazólio a $0,5 \%$ foram classificadas de acordo com seus aspectos morfológicos em quatro classes de vigor: sementes vigorosas, sementes viáveis, sementes inviáveis e a quarta classe que corresponde a um outro fator de grande relevância, em espécies florestais, a presença de sementes verdes que são consideradas inviáveis.

$\mathrm{Na}$ avaliação da viabilidade das sementes pelo teste de tetrazólio foi observada diferença entre os cinco lotes submetidos aos métodos de pré-condicionamento e tempo de embebição.

Em sementes pré-condicionadas em papel por 18 horas a $30^{\circ} \mathrm{C}$, foi verificado que o tempo de duas horas de permanência em solução de tetrazólio a $0,5 \%$, possibilitou diferenças significativas entre os lotes, indicando os lotes 1 e 4 com viabilidade alta $99 \%$ e $96 \%$ em relação aos demais. Estes dados foram coincidentes com os resultados obtidos na determinação do vigor, o que não ocorreu em relação à germinação que detectou diferenças entre os lote 1 e 4 . Esses resultados podem ser explicados uma vez que no lote 4 foi observado um grande número de plântulas anormais infeccionadas, indicando a interferência de fungos nos resultados (Tabela 4).

$\mathrm{Na}$ Figura 3 pode-se observar as diferentes colorações das sementes de $S$. virgata encontradas ao final do teste de tetrazólio, nos períodos de uma, duas e três horas de permanência na solução de tetrazólio com concentração de $0,5 \%$.

Tabela 3 - Resultados médios obtidos nos testes de vigor em lotes de sementes de Sesbania virgata em diferentes métodos de pré-condicionamento e tempo de permanência em solução de tetrazólio.

\begin{tabular}{|c|c|c|c|c|c|c|}
\hline \multicolumn{7}{|c|}{ Pré-condicionamento* } \\
\hline \multirow{3}{*}{ Lotes } & & Papel & & & Água & \\
\hline & \multicolumn{6}{|c|}{ Tempo (h) } \\
\hline & 1 & 2 & 3 & 1 & 2 & 3 \\
\hline 1 & $97,0 \mathrm{a}$ & 90,0 a B & 96,0 a $\mathrm{AB}$ & 96,0 a & $98,0 \mathrm{a}$ & $99,0 \mathrm{a}$ \\
\hline 2 & $91,0 \mathrm{ab}$ & $79,0 \mathrm{bc} \mathrm{B}$ & $90,0 \mathrm{ab} \mathrm{A}$ & $87,0 \mathrm{~b}$ & $88,0 \mathrm{~b}$ & $93,0 \mathrm{ab}$ \\
\hline 3 & $87,0 \mathrm{bc}$ & 75,0 с B & $91,0 \mathrm{ab} \mathrm{A}$ & $90,0 \mathrm{ab}$ & $88,0 \mathrm{~b}$ & $88,0 \mathrm{~b}$ \\
\hline 4 & $80,0 \mathrm{~cd}$ & $83,0 \mathrm{ab} \mathrm{A}$ & $84,0 \mathrm{~b} \mathrm{~A}$ & $77,0 \mathrm{c}$ & $77,0 \mathrm{c}$ & $78,0 \mathrm{c}$ \\
\hline 5 & $72,0 \mathrm{~d}$ & $57,0 \mathrm{~d} B$ & 71,0 c A & $73,0 \mathrm{c}$ & $75,0 \mathrm{c}$ & $78,0 \mathrm{c}$ \\
\hline $\mathrm{CV}(\%)$ & \multicolumn{6}{|c|}{6,59} \\
\hline
\end{tabular}

* Médias com a mesma letra, minúscula nas colunas e maiúscula nas linhas, não diferem entre si pelo teste de Tukey $(\mathrm{P}<0,05 \%)$. 

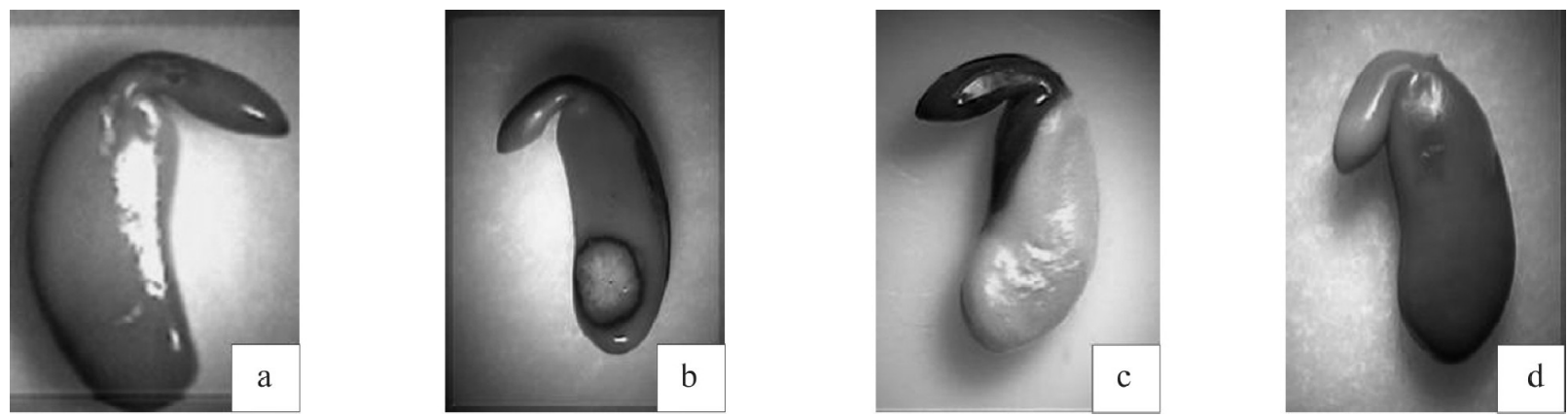

Figura 2 - Classificação das sementes de Sesbania virgata, na solução de tetrazólio, em quatro classes de vigor. Legenda: (a) sementes vigorosas com cotilédone e embrião colorido; (b) sementes viáveis, com lesões no cotilédone sem atingir o embrião; (c) sementes inviáveis apresentando lesões próximas ao eixo embrionário; (d) sementes verdes e inviáveis.

Tabela 4 - Resultados médios obtidos nos testes de viabilidade em lotes de sementes de Sesbania virgata em diferentes métodos de pré-condicionamento e tempo de permanência em solução de tetrazólio.

\begin{tabular}{|c|c|c|c|c|c|c|}
\hline \multirow{4}{*}{ Lotes } & \multicolumn{6}{|c|}{ Pré-condicionamento* } \\
\hline & \multicolumn{3}{|c|}{ Papel } & \multicolumn{3}{|c|}{ Água } \\
\hline & \multicolumn{6}{|c|}{ Tempo (h) } \\
\hline & 1 & 2 & 3 & 1 & 2 & 3 \\
\hline 1 & $99,0 \mathrm{a}$ & 99,0 a $A$ & 100,0 a $\mathrm{A}$ & $98,0 \mathrm{a}$ & $100,0 \mathrm{a}$ & $100,0 \mathrm{a}$ \\
\hline 2 & $100,0 \mathrm{a}$ & $92,0 \mathrm{ab} \mathrm{B}$ & 97,0 a $\mathrm{AB}$ & $100,0 \mathrm{a}$ & $97,0 \mathrm{ab}$ & $98,0 \mathrm{a}$ \\
\hline 3 & 96,0 a & 89,0 b B & 98,0 a $\mathrm{A}$ & $96,0 \mathrm{ab}$ & $94,0 \mathrm{ab}$ & $94,0 \mathrm{ab}$ \\
\hline 4 & $94,0 \mathrm{ab}$ & 96,0 a $A$ & 94,0 a $\mathrm{A}$ & $94,0 \mathrm{ab}$ & $94,0 \mathrm{ab}$ & $90,0 \mathrm{~b}$ \\
\hline 5 & $89,0 \mathrm{~b}$ & 70,0 c B & 86,0 b A & $89,0 \mathrm{~b}$ & $91,0 \mathrm{~b}$ & $89,0 \mathrm{~b}$ \\
\hline $\mathrm{CV}(\%)$ & \multicolumn{6}{|c|}{8,64} \\
\hline
\end{tabular}

*Médias com a mesma letra minúscula nas colunas e maiúscula nas linhas, não diferem entre si pelo teste de Tukey (P $\leq 0,05 \%)$.
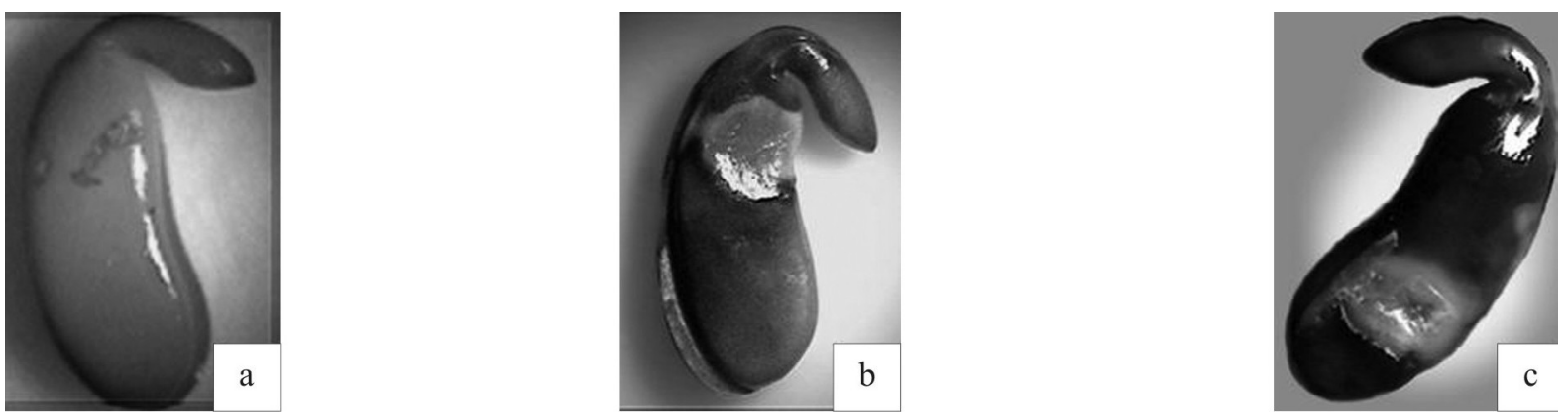

Figura 3 - Aspectos das sementes de Sesbania virgata nos três tempos de permanência em solução de tetrazólio com concentração de 0,5\%. Legenda: (a) uma hora; (b) duas horas; (c) três horas.

De acordo com os resultados obtidos, tanto o précondicionamento em água quanto em papel por 18 horas, são eficientes para auxiliar na retirada do tegumento de $S$. virgata, porém o condicionamento em papel permitiu maior diferenciação entre os cinco lotes, por causa da absorção lenta de água pelas sementes. Os resultados desta pesquisa evidenciaram que o pré-condicionamento em papel com embebição das sementes em solução de tetrazólio a $0,5 \%$ por 2 horas é a metodologia mais adequada para a espécie. 


\section{CONCLUSÃO}

O tratamento mais eficiente para superação da dormência em lotes de sementes de Sesbania virgata foi a escarificação mecânica com a utilização da lixa.

O pré-condicionamento em papel por 18 horas a uma temperatura de $30^{\circ} \mathrm{C}$ e a imersão das sementes por duas horas em solução de tetrazólio a $0,5 \%$ é um método adequado para avaliação da viabilidade Sesbania virgata.

\section{REFERÊNCIAS BIBLIOGRÁFICAS}

ALVES, M. C. S.; MEDEIROS-FILHO, S.; ANDRADENETO, M.; TEÓFILO, E. M. Superação da dormência em sementes de Bauhinia monandra Britt. e Bauhinia ungulata L. Caesalpinoideae. Revista Brasileira de Sementes, Brasília, v. 22, n. 2, p. 151-157, 2000.

AMARAL, L. I. V.; PEREIRA, M. F. A.; CORTEZZO, A. L. Quebra de dormência em sementes de Bixa orellana. Revista Brasileira de Fisiologia Vegetal, Brasília, v. 7, n. 2, p. 151-157, 1995.

ARAÚJO, E. F.; ARAÚJO, R. F.; GAlVÃO, J. C. C. Superação da dureza de sementes e frutos de Stylosanthes scabra J. Vogel e seu efeito na germinação. Revista Brasileira de Sementes, Brasília, v. 24, n. 2, p. 77-81, 2002.

ARAÚJO, E. C.; MENDONÇA, A. V. R.; BARROSO, D. G.; LAMÔNICA, K. R.; SILVA, R. F. Caracterização morfológica de frutos, sementes e plântulas de Sesbania virgata (CAV) PERS. Revista Brasileira de Sementes, Brasília, v. 26, n. 1, p. 104-109, 2004.

BHERING, M. C.; DIAS, D. S. F. S.; BARROS, D. F. Adequação da metodologia do teste de tetrazólio para avaliação da qualidade fisiológica de sementes de melancia. Revista Brasileira de Sementes, Brasília, v. 27, n. 1, p. 176182, 2005.

BITTENCOURT, S. R. M.; VIEIRA, R. D. Use of reduced concentrations in the viability of peanut seed lots. Seed Science and Techology, Zurich, v. 2, p. 75-82, 1997.

BRASIL. Ministério da Agricultura e Reforma Agrária. Regras para análise de sementes. Brasília, DF: SNDA/ DNDV/CLAV, 1992. 364 p.

COPELAND, T. G.; BRUCE, C. F.; MIDYETTE JUNIOR, Y. $M$. The unofficial application of tetrazolium tests as an aid in checking germination claims. Proceedings of the Association of official Seed Analysts, East Lansing, v. 49, p. 134-141, 1959.

COSTA, N. P.; FRANÇA-NETO, J. B.; KRZYZANOWSKI, F. C.; HENNING, A. A.; PEREIRA, F. R. Efeitos da temperatura e do período de embebição de sementes de soja, para o teste de tetrazólio. Arquivos de Biologia e Tecnologia, Curitiba, v. 40, p. 169-177, 1998.

EVANS, D. O. What is Sesbania?: botany, taxonomy, plant geography and natural history of the perennial members of the genus. In: MACKLIN, B.; EVANS, D. O. (Eds.). Perennial sesbania species in agroforestry systems. Waimanalo: Nitrogen Eixing tree Association, 1990. p. 16.

FERREIRA, A. G.; BORGHETTI, F. Germinação do básico ao aplicado. Londrina: [s.n.], 2004. 316 p.

FERREIRA, D. F. Manual do sistema sisvar para análise estatística. Lavras: UFLA, 2000. 63 p.

FERREIRA, R. A.; VIEIRA, M. G. G. C.; PINHO, E. V. R. von; TONETTI, O. A. O. Morfologia da semente e de plântulas e avaliação da viabilidade da semente de Sucupira Branca (Pterodon pubescens Benth-FABACEAE) pelo teste de tetrazólio. Revista Brasileira de Sementes, Brasília, v. 23, n. 1, p. 108-115, 2001.

JAMWAL, V.; DUTT, A. K. Germination response of seeds of Sesbania sesban provenances to different preso wing treatments. Indian Forester, [S.1.], v. 121, p. 1169-1171, 1995.

KRZYZANOWSKI, F. C.; FRANÇA-NETO, J. B.; HENNING, A. A. Relato dos testes de vigor disponíveis para as grandes culturas. Londrina: Abrates, 1991. 55 p.

MAGUIRE, J. D. Seeds of germination aid selection and evaluation for seedling emergence and vigor. Crop Science, Madison, v. 2, p. 176-177, 1962.

MARCOS FILHO. Teste e vigor: importância e utilização. In: KRZYZANOWSKI, F. C.; VIEIRA, R. D.; FRANÇA NETO, J. B. Vigor de sementes: conceito e testes. Londrina: Abrates, 1999. cap. 1, p. 1-20.

MARCOS FILHO. Fisiologia de sementes e plantas cultivadas. Piracicaba: ESALQ, 2005. 495 p. 
OLIVEIRA, L. M. Adequação da metodologia do teste de tetrazólio para avaliação da viabilidade de sementes de melancia (Citrullus lanatus thunb, Mansf). Revista Brasileira de Sementes, Brasília, v. 25, p. 123-128, 2002.

POTT, A.; POTT, V. J. Plantas do pantanal. Corumbá: Embrapa/CPAP/SPI, 1994. 320 p.

PRASAD, P.; NATIYAL, A. R. Physiology of germination in Bauhinia: involvement of seed Coat in inhibition of germination in B. racemosa seeds. Seed Science and Technology, Zurich, v. 24, p. 305-308, 1996.

SMIDERLE, O. J.; SOUSA, R. C. P. Dormência em sementes de Paricarana (Bowdichia virgilioides KunthFABACEAE-PAPILIONIDAE). Revista Brasileira de Sementes, Brasília, v. 25, n. 1, p. 72-75, 2003.

TEIXEIRA, M. C. B. Efeito da temperatura, no potencial hídrico e do pH sobre a embebição e germinação das sementes de quatro espécies do gênero Stylosanthes. 1979.
65 f. Dissertação (Mestrado em Fisiologia Vegetal) Universidade Federal de Viçosa, Viçosa, 1979.

VEAZEY, E. A.; FREITAS, J. C. T.; SCHAMMASS, E. A. Variabilidade da dormência de sementes entre e dentro de espécies de Sesbânia. Scientia Agricola, Piracicaba, v. 57, p. 229-304, 2000.

WEERAKOON, W. L.; SENEVIRATNE, G.; SENEVIRAT, A. M. Flowering, seed production and germination of Sesbania speciosa used as green manure for lowland rice in Sri Lanka. International Rice Research Newsletter, Manila, v. 17, p. 21, 1992

ZAYAT, A. G. Termobiologia da germinação de sementes de Sesbania virgata (FABACEAE). 1996. 68 f. Dissertação (Mestrado em Fisiologia Vegetal) - Universidade Federal de Lavras, Lavras, 1996.

ZUCARELI, C.; MALAVASI, M. M.; FOGAÇA, C. A.; MALAVASI, U. C. Preparo e coloração de sementes de farinha-seca (Albizia hasslerii (chodat) Burr.) para o teste de tetrazólio. Revista Brasileira de Sementes, Brasília, v. 23, n. 2, p. 186-191, 2001. 